\title{
Institutional deliveries and stillbirth and neonatal mortality in the Global Network's Maternal and Newborn Health Registry
}

Shivaprasad S. Goudar ${ }^{1 *}$, Norman Goco², Manjunath S. Somannavar ${ }^{1}$, Avinash Kavi $^{1}$, Sunil S. Vernekar ${ }^{1}$, Antoinette Tshefu ${ }^{3}$, Elwyn Chomba ${ }^{4}$, Ana L. Garces ${ }^{5}$, Sarah Saleem ${ }^{6}$, Farnaz Naqvi ${ }^{6}$, Archana Patel ${ }^{7}$, Fabian Esamai ${ }^{8}$, Carl L. Bose ${ }^{9}$, Waldemar A. Carlo ${ }^{10}$, Nancy F. Krebs ${ }^{11}$, Patricia L. Hibberd ${ }^{12}$, Edward A. Liechty ${ }^{13}$,

Marion Koso-Thomas ${ }^{14}$, Tracy L. Nolen², Janet Moore ${ }^{2}$, Pooja lyer ${ }^{2}$, Elizabeth M. McClure ${ }^{2} \mathbb{B}$, Robert L. Goldenberg ${ }^{15}$ and Richard J. Derman ${ }^{16}$

From Global Network

Virtual. 3-15 Septemeber 2020

\begin{abstract}
Background: Few studies have shown how the move toward institutional delivery in low and middle-income countries (LMIC) impacts stillbirth and newborn mortality.

Objectives: The study evaluated trends in institutional delivery in research sites in Belagavi and Nagpur India, Guatemala, Kenya, Pakistan, and Zambia from 2010 to 2018 and compared them to changes in the rates of neonatal mortality and stillbirth.

Methods: We analyzed data from a nine-year interval captured in the Global Network (GN) Maternal Newborn Health Registry (MNHR). Mortality rates were estimated from generalized estimating equations controlling for within-cluster correlation. Cluster-level analyses were performed to assess the association between institutional delivery and mortality rates.
\end{abstract}

Results: From 2010 to 2018, a total of 413,377 deliveries in 80 clusters across 6 sites in 5 countries were included in these analyses. An increase in the proportion of institutional deliveries occurred in all sites, with a range in 2018 from 57.7 to $99.8 \%$. In 2010, the stillbirth rates ranged from 19.3 per 1000 births in the Kenyan site to 46.2 per 1000 births in the Pakistani site and by 2018, ranged from 9.7 per 1000 births in the Belagavi, India site to 40.8 per 1000 births in the Pakistani site. The 2010 neonatal mortality rates ranged from 19.0 per 1000 live births in the Kenyan site to 51.3 per 1000 live births in the Pakistani site with the 2018 neonatal mortality rates ranging from 9.2 per 1000 live births in the Zambian site to 50.2 per 1000 live births in the Pakistani site. In multivariate modeling, in some but not all sites, the reductions in stillbirth and neonatal death were significantly associated with an increase in the institutional deliveries.

(Continued on next page)

\footnotetext{
*Correspondence: sgoudar@jnmc.edu

${ }^{1}$ KLE Academy of Higher Education and Research Jawaharlal Nehru Medical College, Belagavi, Karnataka, India

Full list of author information is available at the end of the article
}

C C The Author(s). 2020 Open Access This article is licensed under a Creative Commons Attribution 4.0 International License, which permits use, sharing, adaptation, distribution and reproduction in any medium or format, as long as you give appropriate credit to the original author(s) and the source, provide a link to the Creative Commons licence, and indicate if changes were made. The images or other third party material in this article are included in the article's Creative Commons licence, unless indicated otherwise in a credit line to the material. If material is not included in the article's Creative Commons licence and your intended use is not permitted by statutory regulation or exceeds the permitted use, you will need to obtain permission directly from the copyright holder. To view a copy of this licence, visit http://creativecommons.org/licenses/by/4.0/ The Creative Commons Public Domain Dedication waiver (http://creativecommons.org/publicdomain/zero/1.0/) applies to the data made available in this article, unless otherwise stated in a credit line to the data. 
(Continued from previous page)

Conclusions: There was an increase in institutional delivery rates in all sites and a reduction in stillbirth and neonatal mortality rates in some of the GN sites over the past decade. The relationship between institutional delivery and a decrease in mortality was significant in some but not all sites. However, the stillbirth and neonatal mortality rates remain at high levels. Understanding the relationship between institutional delivery and stillbirth and neonatal deaths in resource-limited environments will enable development of targeted interventions for reducing the mortality burden.

Trial registration: The study is registered at clinicaltrials.gov. ClinicalTrial.gov Trial Registration: NCT01073475.

Keywords: Institutional deliveries, Facility births, Stillbirths, Neonatal mortality, Global network

\section{Background}

Since 1990, efforts to reduce child mortality have made an impact across the globe. By 2015, the global underfive mortality rate was reduced by $53 \%$, from 91 per 1000 live births to 43 per 1000 . However, despite the overall progress in under-five child mortality, less progress was made with neonatal mortality, representing $45 \%$ of the 5.9 million under five deaths in 2015 [1]. Furthermore, the burden of death remains unequally distributed, as both sub-Saharan Africa and south Asia recorded a neonatal mortality rate of 29 per 1000 live births, combining for an estimated 2.1 million neonatal deaths recorded in 2015. The burden of stillbirths is similar to that of neonatal mortality and these regions account for a similar proportion of all stillbirths. Most of both neonatal deaths and stillbirths in these regions occur among term or near-term fetuses/neonates. These deaths have been substantially reduced in high-resource settings. To end preventable stillbirths and deaths of newborns and reach the United Nations Sustainable Development Goal (SDG) (3.2) by 2030 (with all countries reducing neonatal mortality to no more than 12 per 1000 live births), success must be achieved in reducing stillbirths and neonatal mortality [2, 3]. Most stillbirths occur during labor and most neonatal deaths occur shortly after delivery [4-7]. Globally, intrapartum-related complications are estimated as the cause of as much as $60 \%$ of stillbirths and $23 \%$ of neonatal mortality [8]. Skilled birth attendance and an institutional environment capable of providing effective obstetric and neonatal care are needed to significantly reduce stillbirths and neonatal deaths $[9,10]$. While delivery in a health facility is assumed to improve birth outcomes, the existing evidence to date has shown contradicting results, particularly in areas where enabling environments are constrained [11-13]. For example, one recent study from Ghana observed that facility delivery was not associated with decreased risk of maternal or neonatal mortality [13].

To date, few prospective studies have assessed the impact of the shift from home births to delivery in health facilities on stillbirths and neonatal mortality across lowresource settings. In a population-based pregnancy registry, we sought to evaluate the trends toward institutional delivery and associated stillbirth and neonatal mortality rates in the Eunice Kennedy Shriver National Institute of Child Health and Human Development Global Network for Women's and Children's Health Research (GN) sites from January 2010 to December 2018.

\section{Methods}

This study is an analysis of 2010-2018 data from the Maternal Newborn Health Registry (MNHR) of the GN [14]. The MNHR is a prospective, population-based surveillance study of pregnant women and their pregnancy outcomes. From the MNHR, six study sites with complete data over this period were selected for inclusion. These sites included: Eldoret, Kenya; Lusaka, Zambia; Belagavi, Karnataka State and Nagpur, Maharashtra State, India; Thatta, Pakistan; and Chimaltenango, Guatemala. The study population at each site is derived from geographically defined clusters with 300 or more births per year. The MNHR staff enrolled all consenting pregnant women who were residents of the cluster and collected outcome information following delivery and at 42 days postpartum.

Table 1 describes the location, the clusters, and the health institutions contributing to the MNHR for this analysis. The MNHR dataset for this analysis (2010 to 2018) excluded outcomes for women lost to follow-up prior to delivery, medically terminated pregnancies or those resulting in miscarriage, and infants weighing $<1000 \mathrm{~g}$ at birth. Early pregnancy losses were excluded because the objective was to assess outcomes associated with facility delivery and those $<1000 \mathrm{~g}$ were generally not considered viable in the study facilities. To evaluate trends, we restricted analyses to clusters that contributed to the full study period.

Institutional delivery was defined as delivery at either a hospital or clinic (primary health center or community health center). Community deliveries included those that occurred at home (generally the mother's home or birth attendant's home). Stillbirth rates were defined as deaths prior to delivery among all births $\geq 28$ weeks gestation or $>1000 \mathrm{~g}$ birthweight if gestational age was unavailable (events per 1000 births). 
Table 1 Site Descriptions

\begin{tabular}{|c|c|c|c|}
\hline $\begin{array}{l}\text { Site } \\
\text { (CoORdinating Center) }\end{array}$ & LOCATION & No. of Continuing Clusters & No. and Type of Health Facilities \\
\hline \multicolumn{4}{|l|}{ Africa } \\
\hline $\begin{array}{l}\text { Kenya } \\
\text { (Eldoret) }\end{array}$ & $\begin{array}{l}\text { Western region of Kenya in counties of Busia, } \\
\text { Bungoma, and Kakamega }\end{array}$ & 16 & $\begin{array}{l}20 \text { health centers } \\
3 \text { referral hospitals }\end{array}$ \\
\hline $\begin{array}{l}\text { Zambia } \\
\text { (Lusaka) }\end{array}$ & $\begin{array}{l}\text { Kafue and Chongwe districts south and east } \\
\text { of Lusaka }\end{array}$ & 10 & $\begin{array}{l}8 \text { health posts } \\
3 \text { district hospitals } \\
1 \text { tertiary referral hospital }\end{array}$ \\
\hline \multicolumn{4}{|l|}{ Latin America } \\
\hline $\begin{array}{l}\text { Guatemala } \\
\text { (Chimaltenango) }\end{array}$ & Western Highlands of Guatemala & 11 & $\begin{array}{l}42 \text { health posts } \\
30 \text { health centers } \\
1 \text { tertiary level referral hospital }\end{array}$ \\
\hline \multicolumn{4}{|l|}{ AsIA } \\
\hline $\begin{array}{l}\text { Belagavi, India } \\
\text { (Belagavi) }\end{array}$ & Northwestern corner of state of Karnataka & 12 & $\begin{array}{l}18 \text { primary health centers } \\
8 \text { secondary level hospitals } \\
3 \text { tertiary level hospitals }\end{array}$ \\
\hline $\begin{array}{l}\text { Nagpur, India } \\
\text { (Nagpur) }\end{array}$ & Located within the state of Maharashtra & 19 & $\begin{array}{l}20 \text { primary health centers } \\
119 \text { sub-centers } \\
10 \text { tertiary level hospitals }\end{array}$ \\
\hline $\begin{array}{l}\text { Pakistan } \\
\text { (Thatta) }\end{array}$ & $\begin{array}{l}\text { Two sub-districts of Thatta district in southern } \\
\text { Sindh province }\end{array}$ & 12 & $\begin{array}{l}47 \text { primary health clinics } \\
25 \text { secondary care facilities } \\
3 \text { tertiary level referral hospitals }\end{array}$ \\
\hline
\end{tabular}

Descriptive analyses were performed. For each mortality outcome, annual estimates, and 95\% confidence intervals were obtained from generalized linear models with a Poisson distribution assumption and log link with generalized estimating equations controlling for within-cluster correlation. Parameters in the model include site and year as well as their interaction, with year treated categorically in order not to assume a linear trend over time although a test for a linear trend was completed. Models were also run adjusting for potential confounders including age, maternal education, parity, multiple births, and infant birth weight. Within site estimates were obtained for all deliveries. Cluster-level mortality rates were modeled as a function of institutional delivery rates using repeated measures beta logistic models to account for correlation within clusters across time. The partial correlation coefficient $(\rho)$ between institutional delivery rates and each mortality outcome was also calculated accounting for the repeated measures within cluster across time in order to assess the association between the institutional delivery rate and the outcome, while accounting for the potential confounders. All analyses were conducted using SAS v.9.4 (Cary, NC).

\section{Results}

From 2010 to 2018, a total of 413,377 deliveries were included in these analyses (Fig. 1), with a range across sites of 58,686 deliveries in the Guatemalan site to 79,011 deliveries in the Nagpur site (Table 2). Overall, $82.6 \%$ of the pregnant women in this cohort were between the ages of $20-35$, with the Kenyan (22.2\%) and Zambian
(24.6\%) sites having the largest proportion of women below the age of 20 . Approximately $80 \%$ of women had a primary level of education or higher. However, the Pakistani site reported that $85.8 \%$ of women had no formal education. Regarding parity, nearly $30 \%$ of the cohort in the Kenyan, Zambian and Guatemalan sites, greater than $40 \%$ in the Belagavi and Nagpur sites, and less than $20 \%$ in the Pakistani site were nulliparous. In contrast, more than $30 \%$ of the women in the Kenyan, Zambian, and Guatemalan sites and nearly half in the Pakistani site reported two or more prior births, while the Belagavi and Nagpur sites reported that less than $10 \%$ of the women had two or more prior births. The proportion of women with at least one antenatal care visit was nearly $100 \%$ for all sites except for the Pakistani site, which was just below 90\%. Among all sites, between 47 and $50 \%$ of infants were female and less than $3 \%$ were the result of a multiple gestation. The African sites reported the greatest proportion of infants with a birthweight $\geq 2500 \mathrm{~g}$ ( $96.1 \%$ for the Kenyan site and $93.5 \%$ for the Zambian site), while the other sites reported $\geq 2500$ g birth weight rates between 78.9 and $84.0 \%$.

There were substantial increases in institutional deliveries observed for all sites (Table 3), with the largest increases at the Kenyan site (35.8 to $86.7 \%$ for 2010 to 2018), the Zambian site (50.5 to 88.2\%), the Pakistani site (46.1 to $72.5 \%$ ), and the Guatemalan site (28.2 to $57.7 \%$ ). The proportion of institutional deliveries in the two Indian sites were already above $90 \%$ in 2010 and increased to nearly 99\% or greater by 2018 (Belagavi: 92.7 to $98.7 \%$; 


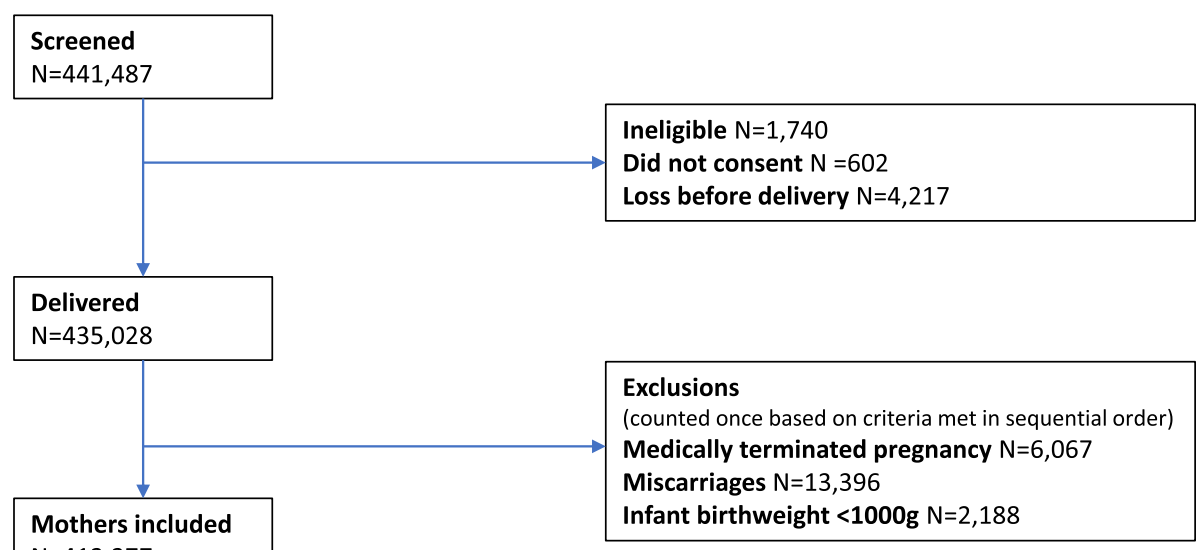

Fig. 1 CONSORT diagram - Enrollment and deliveries

Nagpur: 90.0 to $99.8 \%)$. Trends in the proportion of deliveries attended by a trained health worker also increased over time and were generally consistent with the rates for institutional deliveries (data not shown). While rates of caesarean deliveries also increased over time, they were generally low for the African sites ( $<3 \%$ across all years), rose from 6 to $15 \%$ in the Pakistani site, and were greater than $10 \%$ in 2010 increasing to between 28 and 38\% in 2018 for the Indian and Guatemalan sites, respectively (data not shown).

Figure 2 displays stillbirth and neonatal mortality rates for each site by year. In general, the overall rates for each outcome decreased over time for most sites, with year-toyear fluctuation. The Pakistani site consistently reported the highest stillbirth and neonatal mortality rates.

Table 3 presents results for trends in stillbirth and neonatal mortality rates over time. In the unadjusted analyses, every site showed at least a modest reduction of stillbirth rates from 2010 to 2018 . When adjusting for covariates, the test for linear trend over time was significant for stillbirths only for the Asian sites, but not for the African or Guatemalan sites. Comparing 2010 to 2018, every site had at least a small reduction in the neonatal mortality rates. In the adjusted analyses, neonatal mortality was reduced significantly for the Zambian, Pakistani, Guatemalan and Belagavi sites. In the Nagpur site, the overall unadjusted stillbirth rate fell from 28.6 to 11.5 per $1000(p<0.0001)$; however, the adjusted model for neonatal mortality failed to converge.

In the cluster-level analyses to assess the association between institutional delivery rates and stillbirth rates (Table 3), evidence for an association was observed for stillbirths for the Zambian, Belagavi, Nagpur, Guatemalan and Pakistani sites. Neonatal mortality rates were associated with increases in institutional delivery for the Kenyan, Zambian, Belagavi, and Nagpur sites. In each of these sites, the partial correlation coefficients $(\rho)$ between institutional delivery rates and stillbirths and/or neonatal mortality rates were negative and the odds ratios (OR) for a 1 unit increase in institutional delivery were less than one, suggesting that stillbirth and/or neonatal mortality rates were lower when institutional delivery rates were higher. However, generally these results suggest that the observed associations between institutional delivery and mortality outcomes were relatively small.

\section{Discussion}

This study analyzed 9 years (2010 to 2018) of pregnancy and delivery outcome data from six sites within the GN MNHR. The proportion of institutional deliveries increased across all GN sites. The shift was associated with some statistically significant decreases in stillbirth and neonatal mortality over the same period; however, overall, these changes were modest. Among the African sites, a large increase in institutional births was observed in the Zambian site and at the cluster level, higher institutional birth rates were associated with lower stillbirth and neonatal mortality rates. However, in Kenya, a large increase in institutional deliveries was also observed, with no significant association between institutional delivery rates and stillbirths and neonatal mortality rates.

The proportion of institutional deliveries in the Guatemalan site doubled over time, yet in 2018 institutional deliveries still accounted for less than $60 \%$ of all deliveries. There was, however, no significant decrease in stillbirth rates over time. Along with the increase in institutional deliveries, a significant decrease in the stillbirth and neonatal mortality rates was observed, but with yearto-year fluctuation.

Among the Asian sites, smaller increases in institutional deliveries were observed in the two Indian sites Belagavi and Nagpur - with greater than $90 \%$ of births occurring in health facilities in 2010 and greater than 
Table 2 Maternal and infant demographic and clinical characteristics by site

\begin{tabular}{|c|c|c|c|c|c|c|}
\hline & Kenya & Zambia & Guatemala & Belagavi & Nagpur & Pakistan \\
\hline Deliveries & 73,896 & 62,382 & 58,686 & 78,916 & 79,011 & 60,486 \\
\hline \multicolumn{7}{|l|}{ Maternal Age, N (\%) } \\
\hline$<20$ & $16,274(22.2)$ & $15,310(24.6)$ & $9792(16.7)$ & 8437 (10.7) & $1718(2.2)$ & $2187(3.6)$ \\
\hline $20-35$ & $53,873(73.5)$ & $42,002(67.4)$ & $42,775(72.9)$ & $70,270(89.1)$ & $76,945(97.4)$ & $54,746(90.7)$ \\
\hline$>35$ & $3127(4.3)$ & $5015(8.0)$ & $6109(10.4)$ & $186(0.2)$ & $324(0.4)$ & $3455(5.7)$ \\
\hline \multicolumn{7}{|l|}{ Maternal Education, N (\%) } \\
\hline No formal education & $1653(2.3)$ & $5445(8.8)$ & $10,051(17.1)$ & $12,629(16.1)$ & $2491(3.2)$ & $51,831(85.8)$ \\
\hline Primary or Secondary & $67,043(91.5)$ & $55,746(89.6)$ & $46,156(78.7)$ & $58,340(74.3)$ & $62,608(79.3)$ & $7588(12.6)$ \\
\hline University + & $4598(6.3)$ & $1007(1.6)$ & $2472(4.2)$ & $7579(9.6)$ & $13,828(17.5)$ & $968(1.6)$ \\
\hline \multicolumn{7}{|l|}{ Parity, N (\%) } \\
\hline 0 & $21,236(29.0)$ & $18,103(29.0)$ & $16,863(28.7)$ & $32,053(40.8)$ & $38,783(49.1)$ & $11,028(18.7)$ \\
\hline $1-2$ & $28,495(38.9)$ & 23,968 (38.4) & $22,329(38.1)$ & $41,439(52.7)$ & $38,384(49.6)$ & $19,544(33.1)$ \\
\hline$>2$ & $23,570(32.2)$ & $20,279(32.5)$ & $19,491(33.2)$ & $5068(6.5)$ & $1810(2.3)$ & $28,403(48.2)$ \\
\hline At least one antenatal care visit & $72,430(98.0)$ & $62,184(99.7)$ & $56,422(96.2)$ & $78,884(100)$ & $78,841(99.8)$ & $54,013(89.4)$ \\
\hline Births & 74,814 & 62,999 & 59,051 & 79,479 & 79,628 & 61,187 \\
\hline \multicolumn{7}{|l|}{ Infant Gender, N (\%) } \\
\hline Male & $37,730(50.5)$ & $32,416(51.5)$ & 29,993 (50.9) & $41,011(51.6)$ & $41,374(52.2)$ & $31,591(52.0)$ \\
\hline Female & $36,987(49.5)$ & $30,518(48.5)$ & $28,987(49.1)$ & $38,403(48.4)$ & $37,953(47.8)$ & $29,183(48.0)$ \\
\hline \multicolumn{7}{|l|}{ Infant Birthweight, N (\%) } \\
\hline $1000-1499 \mathrm{~g}$ & $333(0.4)$ & $386(0.6)$ & $406(0.7)$ & $874(1.1)$ & $1027(1.3)$ & $1208(2.0)$ \\
\hline $1500-2499 \mathrm{~g}$ & $2594(3.5)$ & $3684(5.9)$ & $9016(15.3)$ & $12,779(16.1)$ & $12,857(16.2)$ & $11,593(19.1)$ \\
\hline$\geq 2500 \mathrm{~g}$ & $71,743(96.1)$ & $58,863(93.5)$ & $49,543(84.0)$ & $65,779(82.8)$ & $65,377(82.5)$ & $47,950(78.9)$ \\
\hline \multicolumn{7}{|l|}{ Multiple Birth, N (\%) } \\
\hline Yes & $1790(2.4)$ & $1214(1.9)$ & $720(1.2)$ & $1121(1.4)$ & $1226(1.5)$ & $1372(2.3)$ \\
\hline No & $72,970(97.6)$ & $61,754(98.1)$ & $58,274(98.8)$ & $78,325(98.6)$ & $78,266(98.5)$ & $59,425(97.7)$ \\
\hline
\end{tabular}

MNH Registry 2010-2018 deliveries excluding women lost to follow-up prior to delivery, miscarriages/medical terminations and births $<1000 \mathrm{~g}$. Infant birthweight includes measured and estimated values

$98 \%$ by the end of 2018 . For both Indian sites, lower stillbirth and neonatal mortality rates were associated with higher institutional delivery rates. In the Pakistani site, the proportion of institutional deliveries moderately increased from 2010 to 2018 and there were significant decreases in the stillbirth and neonatal mortality rates. However, there was only a significant association between stillbirth rates and institutional delivery rates.

Prior and during the time of this study, the governments of many low and middle-income countries (LMIC) have encouraged institutional delivery through incentive programs (e.g., conditional cash transfers and removal of user fees) as a strategy to improve maternal and newborn outcomes $[15,16]$. Evaluations of these strategies have demonstrated varied results in increasing institutional deliveries [17-19].

A recently published study of the major determinants of facility birth on mortality outcomes through a secondary analysis of surveillance data in Ghana found that facility delivery did not result in improved survival for newborns [13]. Investigators assessed the quality of care of obstetric and newborn services among the facilities in the study area. The study highlighted the need to improve the quality of obstetric and newborn care in order to reduce mortality. Some studies have shown that institutional deliveries may reduce perinatal mortality attributed to intrapartum complications [20] and may reduce neonatal mortality [17]. In our study, we observed an increase in institutional deliveries at each of the research sites and identified an associated decrease in neonatal mortality in four of the six sites. Despite these improvements, the neonatal mortality rates remain at high levels when compared with corresponding rates in high-income counties [21]. Further progress may require an enhanced focus on improving the quality of delivery services as well as a corresponding improvement in the overall health systems in LMICs. 
Table 3 Trends in Delivery and Mortality Rates by Site

\begin{tabular}{rll}
\hline \multicolumn{1}{l}{ Year } & Overall Births, N & $\begin{array}{l}\text { Institutio } \\
\text { Delivery }\end{array}$ \\
\hline $\begin{aligned} \text { Kenya } \\
2010\end{aligned}$ & \\
2011 & 9177 & $3242(35.8)$ \\
2012 & 9523 & $3672(39.0)$ \\
2013 & 8905 & $3690(41.9)$ \\
2014 & 8460 & $4236(50.8)$ \\
2015 & 7875 & $5037(64.8)$ \\
2016 & 7761 & $5560(72.5)$ \\
2017 & 7692 & $5890(77.5)$ \\
2018 & 7729 & $5386(70.6)$ \\
\hline
\end{tabular}

Birth-Level Analyses: Adjusted Linear trend $p$-value ${ }^{1}$

Cluster-Level Analyses of mortality outcome with institutional delivery rate (IDR)

Odds ratio for 1 unit increase in IDR ( $p$-value)

Partial correlation coefficient with IDR ( $p$-value)

\section{Zambia}

$\begin{array}{lll}2010 & 7137 & 3571(50.5) \\ 2011 & 7113 & 4070(57.7) \\ 2012 & 6780 & 4458(66.3) \\ 2013 & 6798 & 4666(69.3) \\ 2014 & 6671 & 5171(78.2) \\ 2015 & 7265 & 5936(82.7) \\ 2016 & 7322 & 6054(83.5) \\ 2017 & 7074 & 6048(86.6) \\ 2018 & 6839 & 5968(88.2)\end{array}$

Birth-Level Analyses: Adjusted Linear trend $p$-value ${ }^{1}$

Cluster-Level Analyses of mortality outcome with institutional delivery rate (IDR)

Odds ratio for 1 unit increase in IDR ( $p$-value)

Partial correlation coefficient with IDR ( $p$-value)

\section{Guatemala}

$\begin{array}{lll}2010 & 4042 & 1134(28.2) \\ 2011 & 5900 & 2023(34.5) \\ 2012 & 5843 & 2422(41.7) \\ 2013 & 6761 & 3234(48.1) \\ 2014 & 7010 & 3447(49.5) \\ 2015 & 7326 & 3710(51.0) \\ 2016 & 7905 & 3941(50.2) \\ 2017 & 7410 & 4013(54.4) \\ 2018 & 6854 & 3931(57.7)\end{array}$

Birth-Level Analyses: Adjusted Linear trend $p$-value ${ }^{1}$

Cluster-Level Analyses of mortality outcome with institutional delivery rate (IDR)

Odds ratio for 1 unit increase in IDR ( $p$-value)

Partial correlation coefficient with IDR ( $p$-value)

Overall N $(95 \% \mathrm{Cl})$

Stillbirth rate

(per 1000 births)

Neonatal mortality

$<28$ days rate

(per 1000 live births)

$19.3(14.6,25.5)$
$16.6(12.2,22.5)$
$25.6(20.1,32.6)$
$19.5(14.9,25.6)$
$23.0(18.3,28.7)$
$21.7(17.1,27.5)$
$20.1(16.6,24.3)$
$22.6(19.3,26.5)$
$15.8(12.6,19.7)$
0.4926

$19.0(13.3,27.0)$

$12.3(9.8,15.3)$

$13.6(10.8,17.2)$

$13.8(11.0,17.5)$

$11.5(8.9,14.9)$

$11.0(8.4,14.5)$

$12.6(9.8,16.3)$

$13.6(9.9,18.8)$

$11.8(8.4,16.5)$

0.1419

$0.87(0.5165)$

$-0.04(0.6299)$

$-0.18(0.0414)$

$24.2(18.2,32.1)$

$22.8(17.5,29.6)$

$17.5(12.5,24.6)$

$15.9(12.4,20.4)$

$18.9(14.6,24.6)$

$16.6(12.3,22.5)$

$18.7(14.4,24.4)$

$15.2(11.8,19.7)$

$13.6(10.3,17.9)$

$13.4(8.8,20.5)$

$13.4(8.7,20.7)$

$13.9(10.5,18.4)$

$16.6(13.3,20.7)$

$16.1(12.8,20.2)$

$13.2(9.4,18.5)$

$9.2(6.9,12.3)$

0.0005

0.59 (0.0704)

$0.45(0.0092)$

$-0.23(0.0398)$

$-0.28(0.0127)$

$20.7(16.5,26.0)$

$27.5(21.4,35.4)$

$19.5(15.4,24.7)$

$22.4(18.2,27.5)$

$15.2(11.2,20.7)$

$17.3(13.6,22.1)$

$17.3(13.8,21.8)$

$22.0(18.6,25.9)$

$14.5(11.7,18.0)$

$29.4(25.8,33.5)$

$18.6(14.0,24.9)$

$25.2(21.1,30.0)$

$19.9(15.4,25.6)$

$26.9(23.3,31.0)$

$18.9(14.7,24.3)$

$20.0(15.7,25.4)$

$16.5(13.8,19.7)$

$21.9(18.3,26.3)$

0.4570

0.0324

$0.68(0.0859)$

$-0.40(0.0002)$ 
Table 3 Trends in Delivery and Mortality Rates by Site (Continued)

\begin{tabular}{ll}
\hline Year & Overall Birt \\
& \\
\hline $\begin{array}{l}\text { Belagavi, India } \\
2010\end{array}$ & \\
2011 & 11,922 \\
2012 & 12,263 \\
2013 & 12,831 \\
2014 & 11,793 \\
2015 & 6942 \\
2016 & 6637 \\
2017 & 6254 \\
2018 & 5641 \\
\hline
\end{tabular}

Birth-Level Analyses: Adjusted Linear trend $p$-value ${ }^{1}$

Cluster-Level Analyses of mortality outcome with institutional delivery rate (IDR)

Odds ratio for 1 unit increase in IDR ( $p$-value)

Partial correlation coefficient with IDR ( $p$-value)

\section{Nagpur, India}

$\begin{array}{lll}2010 & 9719 & 8671(90.0) \\ 2011 & 9203 & 8823(96.6) \\ 2012 & 9184 & 8939(98.1) \\ 2013 & 9568 & 9364(98.8) \\ 2014 & 8762 & 8628(99.1) \\ 2015 & 9469 & 9335(99.5) \\ 2016 & 8699 & 8557(99.5) \\ 2017 & 7987 & 7913(99.8) \\ 2018 & 7037 & 6971(99.8)\end{array}$

Birth-Level Analyses: Adjusted Linear trend $p$-value $e^{1,2}$

Cluster-Level Analyses of mortality outcome with institutional delivery rate (IDR)

Odds ratio for 1 unit increase in IDR ( $p$-value)

Partial correlation coefficient with IDR ( $p$-value)

\section{Pakistan}

$\begin{array}{ll}2010 & 8088 \\ 2011 & 8120 \\ 2012 & 6890 \\ 2013 & 7033 \\ 2014 & 6844 \\ 2015 & 6396 \\ 2016 & 6089 \\ 2017 & 5958 \\ 2018 & 5769\end{array}$

Birth-Level Analyses: Adjusted Linear trend $p$-value ${ }^{1}$

Cluster-Level Analyses of mortality outcome with institutional delivery rate (IDR)

Odds ratio for 1 unit increase in IDR ( $p$-value)

Partial correlation coefficient with IDR ( $p$-value)

\section{Institutional \\ Institutional
Delivery N (\%) \\ $10,961(92.7)$ \\ $11,559(94.9)$ \\ $12,173(95.7)$ \\ $11,245(96.1)$ \\ 6529 (94.8) \\ $6360(96.6)$ \\ $6086(98.0)$ \\ $5492(97.9)$ \\ 5079 (98.7)}

Overall N $(95 \% \mathrm{Cl})$

Stillbirth rate

(per 1000 births)

Neonatal mortality

$<28$ days rate

(per 1000 live births)

$21.5(17.7,26.0)$
$20.7(16.5,26.0)$
$20.1(17.3,23.3)$
$15.0(12.8,17.6)$
$15.8(12.7,19.6)$
$14.1(10.8,18.3)$
$13.6(10.7,17.2)$
$11.2(9.6,13.0)$
$9.7(7.3,13.0)$
0.0049

$24.4(20.3,29.2)$

$21.9(16.3,29.4)$

$21.3(18.0,25.1)$

$23.6(20.7,26.9)$

$22.0(19.1,25.4)$

$18.5(16.1,21.3)$

$16.6(13.9,19.7)$

$18.1(16.4,20.1)$

$13.0(10.1,16.7)$

0.0243

$0.04(0.0006)$

$0.08(0.0018)$

$-0.33(0.0011)$

$-0.27(0.0083)$

$28.6(24.9,33.0)$

$23.5(19.8,27.8)$

$20.7(18.0,23.9)$

$17.9(14.7,21.9)$

$22.0(19.0,25.6)$

$21.7(18.2,25.9)$

$23.5(19.8,27.8)$

$18.7(15.6,22.4)$

$17.7(15.3,20.6)$

$20.6(18.2,23.2)$

$16.5(14.1,19.3)$

$18.0(15.4,21.2)$

$11.5(8.8,15.1)$

$<.0001$

$0.04(<.0001)$

$0.22(0.0302)$

$-0.42(<.0001)$

$-0.17(0.0369)$

3677 (46.1)

$46.2(39.3,54.1)$

$51.3(42.7,61.5)$

$4002(50.0)$

$51.4(43.0,61.4)$

$58.3(50.8,66.8)$

3455 (50.8)

$49.1(43.6,55.4)$

$46.5(40.0,54.1)$

4002 (57.7)

$59.5(50.1,70.8)$

$51.7(45.8,58.4)$

4105 (60.6)

$50.9(44.6,58.2)$

$45.0(41.0,49.4)$

3955 (62.7)

$47.0(40.4,54.7)$

$52.8(45.9,60.7)$

3910 (65.0)

$43.1(36.6,50.8)$

$48.3(43.4,53.7)$

4014 (68.1)

$42.1(37.5,47.3)$

$48.3(43.1,54.1)$

4137 (72.5)

$40.8(35.5,46.9)$

$50.2(45.2,55.7)$

$<.0001$

0.0011

$0.50(0.0015)$

$0.86(0.4499)$

$-0.23(0.0259)$

${ }^{1}$ Adjusted linear models control for the following characteristics: maternal age, maternal education, parity, multiple birth, and categorized infant birth weight ${ }^{2}$ The adjusted model for GN11 Nagpur failed to converge due to a low number of cases among Community birth 

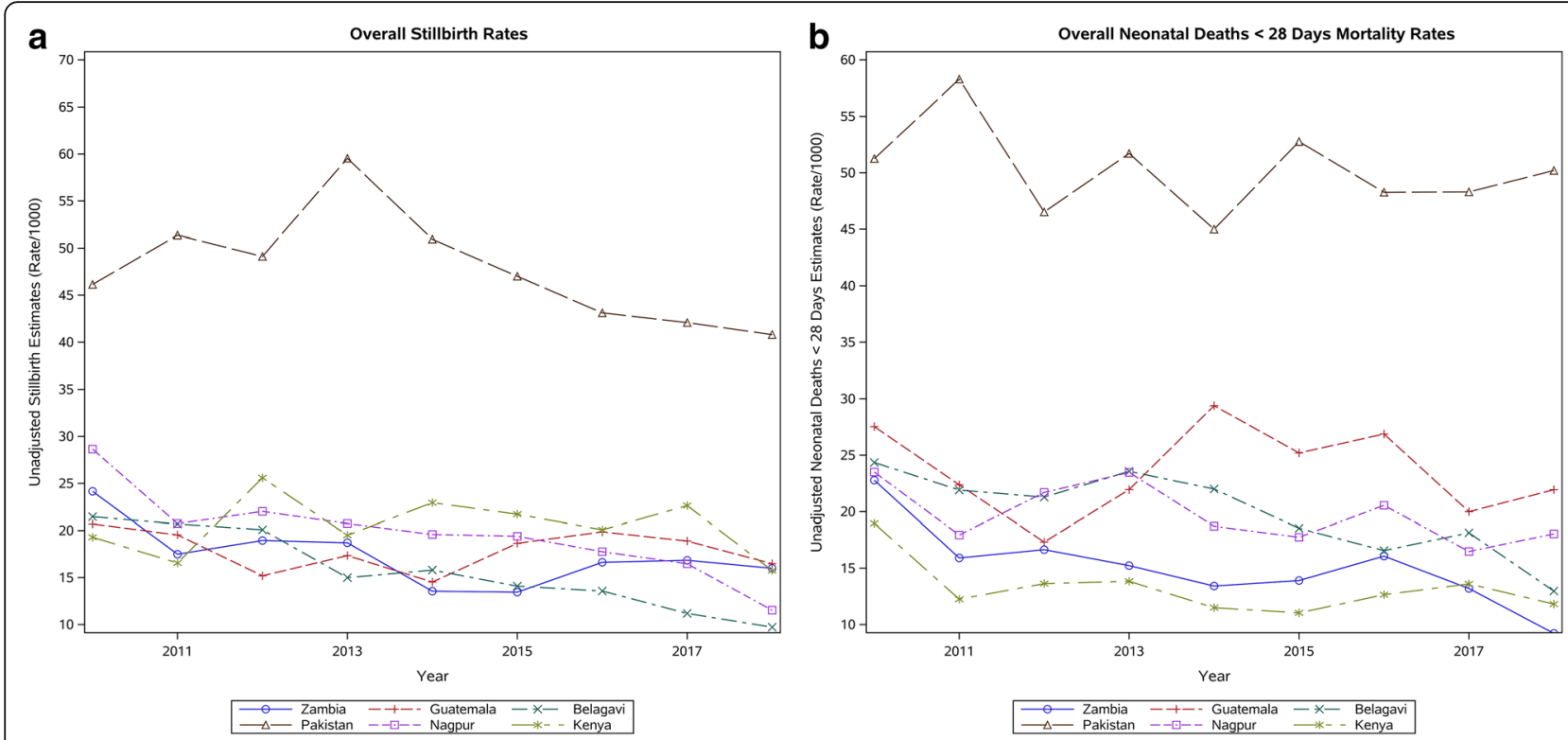

Fig. 2 Stillbirth and neonatal mortality rates - trends over time by country site

Our study includes a significant number of observations and 9 years of data enabling us to measure trends over time. The MNHR incorporates rigorous training of data collectors and close, routine monitoring to help ensure high-quality data. The database for this study included over 400,000 pregnancies and corresponding delivery outcomes to provide a strong framework to analyze trends in institutional delivery and mortality. However, our analyses were limited by the number of factors included in the study and the consistency of variables collected over the study period. This reduced our capacity to explore in depth the associations between institutional deliveries and outcomes.

\section{Conclusions}

While we did observe important increases in institutionbased deliveries, these increases were not consistently associated with decreased stillbirth or neonatal mortality rates. Both stillbirth and neonatal mortality rates remain high in these settings, despite the increases in facility delivery. Research on the factors associated with stillbirth and neonatal mortality in institutional deliveries is needed to develop interventions aimed at reducing those mortalities.

\section{Abbreviations}

GN: Global Network for Women's and Children's Health Research; JSY: Janani Suraksha Yojana; LMIC: Low and middle-income country; MNHR: Maternal and newborn health registry; MDG : Millennium Development Goals; NMR: Neonatal mortality rate; SDG: Sustainable Development Goal

\section{Acknowledgements}

We acknowledge the staff who work on the Global Network's MNHR, including the following:
Democratic Republic of Congo: Antoinette Tshefu*, Adrien Lokangaka, (Kinshasa School of Public Health); Melissa Bauserman, Jacqueline Patterson, Carl L Bose* (UNC Chapel Hill); Kenya: Fabian Esamai*, Irene Marete; Constance Tenge, Paul Nyongesa, Silas Ayunga (Moi University School of Medicine), Edward A. Liechty*, Sherri Bucher (Indiana University); Zambia: Elwyn Chomba*; Musaku Mwenechanya, Melody Chiwila (University Teaching Hospital-Children's Hospital); Waldemar A. Carlo* (University of Alabama at Birmingham); India (Belagavi): Shivaprasad S Goudar*, Sangappa M. Dhaded, Avinash Kavi, Manjunath S Somannavar, M C Metgud, Narayan V Honnungar, Yogesh Kumar S, Sunil S Vernekar, Umesh S Charantimath, Shivanand C Mastiholi, Umesh R. Hundekar, Bhalchandra S. Kodkany (KLE Academy of Higher Education and Research Jawaharlal Nehru Medical College) Ashalata A. Mallapur, Umesh Y. Ramdurg, Sangamesh Rakaraddi (S N Medical College, Bagalkot) Frances J. Jaeger, Richard J. Derman* (Thomas Jefferson University); India (Nagpur): Archana Patel (Lata Medical Research Foundation), P. S. Kalsait, Dr. Prabir Kumar Das, Kunal Kurhe, Patricia L. Hibberd (Boston University); Pakistan: Sarah Saleem*, Saleem Jessani, Farnaz Naqvi, Shiyam Sunder, Zaheer Habib (Aga Khan University), Robert L. Goldenberg* (Columbia University); Bangladesh: Rashidul Haque*, Sk Masum Billah, Atique lqbal Chowdhury (icddr,b), William Petri* (University of Virginia); Guatemala: Ana Garces*, Lester Figueroa (Instituto de Nutrición de Centro América y Panamá), Nancy F. Krebs*, Jamie Westcott (University of Colorado); Data Coordinating Center: Elizabeth M. McClure*, Janet L. Moore, Norman Goco, Stephen D. Litavecz, Vanessa Thorsten, Suchita Parepalli, Tracy Nolen (RTI International); Eunice Kennedy Shriver National Institute of Child Health and Human Development: Marion Koso-Thomas*, Menachem Miodovnik. *MNHR Steering Committee members.

\section{About this supplement}

This article has been published as part of Reproductive Health, Volume 17 Supplement 3, 2020: Global Network MNH. The full contents of the supplement are available at https://reproductive-health-journal. biomedcentral.com/articles/supplements/volume-17-supplement-3.

\section{Authors' contributions}

SSG conceived of the manuscript and wrote the first draft with input from MSS, RLG, RJD, CLB, WAC, NFK, PLH, EAL, MK and EMM. SSV, AK, AT, EC, ALG, $\mathrm{SS}, \mathrm{AP}$, and FE oversaw study implementation, data collection and quality monitoring. NG, JLM, TN and PI performed the statistical analyses. All authors reviewed and approved the final manuscript. 


\section{Funding}

Publication of this supplement is funded by grants from Eunice Kennedy Shriver National Institute of Child Health and Human Development NICHD to the participating sites and to RTI International.

The study was funded by grants (U01 HD040477, U01 HD043475, U01HD043464, U01 HD040657, U01 HD042372, U01 HD040607,

U01HD040636, U01 HD040574, U01 HD40636) from the Eunice Kennedy Shriver National Institute of Child Health and Human Development of the US National Institutes of Health.

\section{Availability of data and materials}

Data from the study will be available at the NICHD data repository (N-DASH): https://dash.nichd.nih.gov/.

\section{Ethics approval and consent to participate}

This study was reviewed and approved by all sites' ethics review committees (Francisco Marroquin University, Guatemala; University of Zambia, Zambia; Moi University, Kenya; Aga Khan University; KLE Academy of Higher Education and Research's Jawaharlal Nehru Medical College, Belagavi; Lata Medical Research Foundation, Nagpur), and the institutional review boards at each U.S. partner university and the data coordinating center (RTI International). All women provided informed consent for participation in the study, including data collection and the follow-up visits.

\section{Consent for publication}

The article was approved for publication by NICHD through its clearance mechanism.

\section{Competing interests}

The authors declare that they have no competing interests.

\section{Author details}

'KLE Academy of Higher Education and Research Jawaharlal Nehru Medical College, Belagavi, Karnataka, India. ${ }^{2}$ RTI International, Durham, NC, USA. ${ }^{3}$ Kinshasa School of Public Health, Kinshasa, Democratic Republic of Congo. ${ }^{4}$ University Teaching Hospital, Lusaka, Zambia. ${ }^{5}$ nstituto de Nutrición de Centroamérica y Panamá, Guatemala City, Guatemala. ${ }^{6}$ Aga Khan University, Karachi, Pakistan. ${ }^{7}$ Lata Medical Research Foundation, Nagpur, India. ${ }^{8}$ Moi University School of Medicine, Eldoret, Kenya. ${ }^{9}$ University of North Carolina at Chapel Hill, Chapel Hill, NC, USA. ${ }^{10}$ University of Alabama at Birmingham, Birmingham, AL, USA. "'University of Colorado School of Medicine, Denver, CO, USA. ${ }^{12}$ Boston University School of Public Health, Boston, MA, USA.

${ }^{13}$ Indiana School of Medicine, University of Indiana, Indianapolis, IN, USA.

${ }^{14}$ Eunice Kennedy Shriver National Institute of Child Health and Human Development, Bethesda, MD, USA. ${ }^{15}$ Department of Obstetrics and Gynecology, Columbia University School of Medicine, New York, NY, USA.

${ }^{16}$ Thomas Jefferson University, Philadelphia, PA, USA.

Received: 28 September 2020 Accepted: 30 September 2020 Published: 17 December 2020

\section{References}

1. UNICEF. Committing to child survival: a promised renewed. New York: Progress Report; 2015

2. The Sustainable Development Goals Report 2016. United Nations; 2016 [cited 2019 Aug 23]. (The Sustainable Development Goals Report). Available from: https://www.un-library.org/economic-and-social-development/thesustainable-development-goals-report-2016_3405d09f-en. Date accessed 14 January 2020.

3. De Bernis L, Kinney MV, Stones W, Ten Hoope-Bender P, Vivio D, Leisher SH, et al. Stillbirths: ending preventable deaths by 2030. Lancet. 2016:387:703-16.

4. Liu L, Oza S, Hogan D, Chu Y, Perin J, Zhu J, et al. Global, regional, and national causes of under-5 mortality in 2000-15: an updated systematic analysis with implications for the sustainable development goals. Lancet. 2016;388:3027-35

5. Lawn JE, Blencowe H, Waiswa P, Amouzou A, Mathers C, Hogan D, et al. Lancet Ending Preventable Stillbirths Series study group; Lancet Stillbirth Epidemiology investigator group. Stillbirths: rates, risk factors, and acceleration towards 2030. Lancet. 2016;387:587-603.
6. Oza S, Cousens SN, Lawn JE. Estimation of daily risk of neonatal death, including the day of birth, in 186 countries in 2013: a vital-registration and modelling-based study. Lancet Glob Health. 2014;2:e635-44.

7. Goudar SS, Goco N, Somannavar MS, Vernekar SS, Mallapur AA, Moore JL, et al. Institutional deliveries and perinatal and neonatal mortality in Southern and Central India. Reprod Health. 2015;12(Suppl 2):S13-S.

8. Roos N, von Xylander SR. Why do maternal and newborn deaths continue to occur? In: Best Practice and Research: Clinical Obstetrics and Gynaecology, vol. 36: Bailliere Tindall Ltd; 2016. p. 30-44.

9. Darmstadt GL, Lee AC, Cousens S, Sibley L, Bhutta ZA, Donnay F, et al. 60million non-facility births: Who can deliver in community settings to reduce intrapartum-related deaths? vol. 107; 2009. p. S89-S112.

10. Moyer CA, Adanu RM, Engmann CM. The relationship between facilitybased delivery and maternal and neonatal mortality in sub-Saharan Africa. Int J Gynec Obstetrics. 2013;122:263-5.

11. Tura G, Fantahun M, Worku A. The effect of health facility delivery on neonatal mortality: systematic review and meta-analysis. BMC Pregnancy Childbirth. 2013;13:18

12. Okeke E, Chari A. Can Institutional Deliveries Reduce Newborn Mortality? Evidence from Rwanda [Internet]. In: Can Institutional Deliveries Reduce Newborn Mortality? Evidence from Rwanda: RAND Corporation; 2014. Available from: https://www.rand.org/pubs/working_papers/WR1072.html. Date accessed 14 January 2020.

13. Gabrysch S, Nesbitt RC, Schoeps A, Hurt L, Soremekun S, Edmond K, et al. Does facility birth reduce maternal and perinatal mortality in Brong Ahafo, Ghana? A secondary analysis using data on 119244 pregnancies from two cluster-randomised controlled trials. Lancet Glob Health. 2019;7:e1074-87.

14. Goudar SS, Carlo WA, McClure EM, Pasha O, Patel A, Esamai F, et al. The maternal and newborn health registry study of the global network for Women's and Children's Health Research. Int J Gynec Obstetrics. 2012;118:190-3.

15. Lim SS, Dandona L, Hoisington JA, James SL, Hogan MC, Gakidou E. India's Janani Suraksha Yojana, a conditional cash transfer programme to increase births in health facilities: an impact evaluation. Lancet. 2010:375:2009-23.

16. Randive B, Diwan V, De Costa A. India's conditional cash transfer Programme (the JSY) to promote institutional birth: is there an association between institutional birth proportion and maternal mortality? PLoS One. 2013;8:e67452

17. McKinnon B, Harper S, Kaufman JS, Bergevin Y. Removing user fees for facility-based delivery services: a difference-in-differences evaluation from ten sub-Saharan African countries. Health Policy Plan. 2015;30:432-41.

18. Calhoun LM, Speizer IS, Guilkey D, Bukusi E. The effect of the removal of user fees for delivery at public health facilities on institutional delivery in urban Kenya. Matern Child Health J. 2018;22:409-18.

19. Chama-Chiliba CM, Koch SF. An assessment of the effect of user fee policy reform on facility-based deliveries in rural Zambia. BMC Res Notes. 2016;9:504.

20. Khanam R, Baqui AH, Syed MIM, Harrison M, Begum N, Quaiyum A, et al. Can facility delivery reduce the risk of intrapartum complications-related perinatal mortality? Findings from a cohort study. J Glob Health. 2018:8:1.

21. Hug L, Alexander M, You D, Alkema L. National, regional, and global levels and trends in neonatal mortality between 1990 and 2017, with scenario-based projections to 2030: a systematic analysis. Lancet Glob Health. 2019;7:e710-20.

\section{Publisher's Note}

Springer Nature remains neutral with regard to jurisdictional claims in published maps and institutional affiliations.

Ready to submit your research? Choose BMC and benefit from:

- fast, convenient online submission

- thorough peer review by experienced researchers in your field

- rapid publication on acceptance

- support for research data, including large and complex data types

- gold Open Access which fosters wider collaboration and increased citations

- maximum visibility for your research: over $100 \mathrm{M}$ website views per year

At $\mathrm{BMC}$, research is always in progress.

Learn more biomedcentral.com/submissions 